\title{
Desafios do direito administrativo global frente à pandemia da COVID-19*
}

\author{
MARCO ANTÔNIO RIBEIRO TURA ${ }^{1}$ \\ EMílio MENDONÇA Dias dA Silva²
}

\section{RESUMO}

Os direitos administrativos domésticos dos estados vêm sofrendo transformações ocasionadas pelo adensamento da globalização e dos fluxos de investimento globais. Se referido processo possuía um desenvolvimento regular, os contextos de crise econômica apresentaram desafios particulares, em razão do aumento de perspectivas nacionalistas. A pandemia da COVID-19 instalou-se justamente nesse cenário, podendo aprofundar as suspeitas em relação à concertação internacional. Para evitar que o direito administrativo global tenha retrocessos, deve a governança global engendrar esforços para que as situações de emergência, como as pandemias, possam ser eficazmente solucionadas, a partir do desenvolvimento das potencialidades locais. O presente artigo buscará descrever o processo de transformação dos direitos administrativos e apresentará os desafios particulares do novo contexto, para que sejam esclarecidas possíveis formas de superar a ameaça do retrocesso.

1 Professor de Arbitragem Comercial Internacional e de Arbitragem de Investimentos Estrangeiros da Escola Brasileira de Direito. Pós-Doutor em Direito Politico e Econômico pela Universidade Presbiteriana Mackenzie de São Paulo. Doutor em Direito Internacional e Integração Econômica pela Universidade do Estado do Rio de Janeiro. Presidente e fundador do Grupo Caraíve. Representante do Brasil no Comitê Global sobre Estado de Direito e Investimentos Internacionais da International Law Association. Julgador na Competição Internacional de Arbitragem de Investimentos da American University em Washington. professor@marcotura.com.br

2 Professor de Solução de Litígios Internacionais da Escola Brasileira de Direito. Mestre e Doutorando em Direito Internacional Público pela Faculdade de Direito da Universidade de São Paulo. Graduado em Direito pela Faculdade de Direito de São Bernardo do Campo. Graduado em Relações Internacionais pelo Centro Universitário Fundação Santo André. Secretário e fundador do Grupo Caraíve. Membro do Grupo de Estudos sobre os BRICS da Universidade de São Paulo. Observador na Competição Internacional de Arbitragem de Investimentos da American University em Washington. executivo@caraive.com.br

* DOI: https://doi.org/10.18601/01236458.n56.08 
Palavras-chave: direito administrativo, governança global, pandemia da COVID-19, direito econômico internacional, investimentos estrangeiros.

\section{RESUMEN}

Los derechos administrativos internos de los estados han experimentado cambios provocados por la intensificación de la globalización y los flujos de inversión global. Si este proceso tuvo un desarrollo regular, los contextos de crisis económica presentaron desafíos particulares, debido al aumento de las perspectivas nacionalistas. Precisamente en este escenario se instaló la pandemia covid-19, lo que puede profundizar las sospechas en relación con la concertación internacional. Para evitar que el derecho administrativo global sufra contratiempos, la gobernanza global debe hacer esfuerzos para que situaciones de emergencia, como las pandemias, puedan resolverse eficazmente, basándose en el desarrollo del potencial local. Este artículo buscará describir el proceso de transformación de los derechos administrativos y presentará los desafíos particulares del nuevo contexto, de manera que se esclarezcan las posibles formas de superar la amenaza de retroceso.

Palabras clave: derecho administrativo, gobernanza global, pandemia de covid-19. Derecho económico internacional, inversiones extranjeras.

\section{ABSTRACT}

State's domestic administrative legal systems have been transformed by the densification of globalization and the increasing of global investments flows. If such process has had a regular development, the economic crisis' context places particular challenges, due to nationalistic perspective growth. COVID-19 pandemic has taken place precisely in such scenery, which can pose deeper suspicious on international concertation. In order to avoid global administrative law retrocession, global governance shall direct efforts toward emergency situations, such as pandemics, can be effectively solved, by means of the development of local potentiality. This article aims to describe the changing process of administrative law and will present challenges coming from the emerging context, for clarifying possible ways to overcome the risk of retrocession.

Keywords: Administrative Law, Global Governance, COVID-19 pandemic, economic international law, foreign investment.

\section{INTRODUÇÃO}

Segundo entendemos, pandemias são caracterizadas como situações em que ocorre uma determinada enfermidade para além do número de casos esperados e alcançando múltiplos países e continentes. 
É, portanto, algo com certa álea, imprevisível, imprevisto ou inevitável; uma situação que pode, no limite, juridicamente, caracterizar uma força maior ou caso fortuito, a quebrar nexos de causalidade na apuração de responsabilidades, o que, ao final, é o que importa para o jurista clássico (Dinca, 2020) ${ }^{3}$.

Pensamos, todavia, na pandemia de maneira mais ampla. Vemos na pandemia uma situação de crise que, como todas as situações semelhantes, força-nos à ação e à reflexão. Afinal, quais são as expectativas realistas para o período de pós-pandemia? Haverá um retorno ao mundo que conhecemos? Pensamos que não. É a nossa própria condição humana, por definição vulnerável (Marcos, 2020), que nos impele a antecipar os novos desafios que se imporão.

A pandemia, ainda que seja a última no mundo das realidades, será apenas a primeira no mundo das idealidades, provocando sentimentos de temor incontroláveis para uns e incompreensíveis para outros e, bem por isso, indescritíveis de um lado a outro.

Vejamos que o mundo viu florescer os nacionalismos e os populismos, paradoxalmente as ideologias que lidaram de maneira mais ineficiente com o avanço do vírus. É justamente por conta do medo, a argila com que se constroem ideologias estúpidas. Apesar de tudo, algo positivo pode ser extraído.

Os Estados nacionais recolocaram na pauta a decisão sobre políticas públicas, mormente de saúde, com a demonstração de que o mercado mundial não se presta bem a lógicas que não sejam à do lucro.

Assim estamos de volta à temática do desenvolvimento das potencionalidades locais, especialmente quanto à tecnologia e mais exatamente quanto à biotecnologia.

O desenvolvimento, porém, historicamente, demanda um esforço coletivo que se corporificou na ação direta ou indireta do Estado. O presente mundo material e cultural, contudo, exige ressignificações para que seu sentido geral seja apreendido e compreendido. O Estado que comparece no processo econômico é em tudo diverso do Estado todo poderoso de outrora.

A soberania, acaso aceita como termo útil, deve ser reinterpretada de modo a traduzir posição dinâmica decorrente de negociações sociais em busca da legitimação da ação estatal. Nessa linha, se a crise reclama uma ação estatal eficiente em vista do desenvolvimento, tal eficiência encontrará sua medida na exata proporção do cálculo adequado do uso dos recursos públicos apenas em empreendimentos que tenham contrapartidas para a solução ótima das demandas sociais.

A definição de quais sejam as demandas sociais e quais sejam as soluções administrativas e econômicas que mais bem as atendam passa por avaliações que exigem a participação de agentes públicos e atores privados em parcerias inovadoras dado incremento da complexidade em virtude do ineditismo dos problemas enfrentados.

3 Uma breve leitura do texto do professor de Bucareste demonstra a procedência de nossa afirmação. Ao jurista clássico importa sobretudo, a questão da responsabilidade e seus elementos caracterizadores. 
Assim, acreditamos que a ação estatal passa por uma mudança na relação entre os setores público e privado em favor de uma noção dialógica, permitindo que haja definição de metas e criação de instrumentos e de meios que possibilitem sua concretização.

A velha administração estatal do cotidiano das contratações de modo verticalizado cede espaço para a nova administração que se horizontaliza na presença do outro precisamente porque não consegue definir com segurança devida o conteúdo do contrato ou, até mesmo, o seu objeto, seja formal ou material.

Nesse texto pretendemos contribuir, por meio da reflexão, com a ação vindoura, nos marcos de uma regulação internacional da economia que se proponha eficaz, equilibrando as relações entre governos engajados na busca de solução aos problemas de sua população e empresas interessadas em ofertar seus produtos e seus serviços para tal finalidade. Quais são as possibilidades do direito internacional econômico atual? E, mais importante, quais são os seus limites?

\section{ANTES DA PANDEMIA: CONSIDERAÇÕES PARA AVALIAÇÃO DO CENÁRIO PÓS-PANDÊMICO}

Antecederam a eclosão da pandemia uma série de transformações decorrentes de crises na matriz econômica global e de mudanças paradigmáticas na compreensão do direito administrativo para além das visões clássicas de um direito eminentemente nacional. Nessa parte pretendemos abordar com mais detalhes tais transformações.

\section{As alterações paradigmáticas do direito administrativo: um ramo gradativamente submetido à governança global}

Para que a conjuntura pós-pandêmica esteja bem caracterizada, reflexões devem ser feitas a respeito do contexto que lhe precede. Algumas breves considerações serão feitas a respeito das alterações paradigmáticas oriundas tanto do aumento do campo de regulação do direito administrativo quanto da globalização, ao longo do século passado e início deste; assim como ponderações a respeito do cenário econômico imediatamente anterior à pandemia serão tecidas, para que se possa entender a contraposição entre as transformações de paradigma teórico e as condições que já se afiguravam. Com o esclarecimento deste panorama, assim, poder-se-á, com melhor precisão, delinear as possíveis condições presentes, durante a pandemia, o que permitirá uma avaliação, ainda que incompleta, do pós-vir em termos de possibilidades às administrações públicas locais e sua inserção global.

No interior dos estados, à medida que se consolidava o estado de bem-estar social, o campo de atividade da administração pública foi significativamente ampliado. A administração pública passou a assumir funções de prestação diretas de serviços em campos sensíveis ao interesse coletivo, como forma de diminuir as externalidades negativas do mercado. 
No entanto, apresentadas as dificuldades e a possível ineficiência da administração pública, mesmo nestes campos, o estado de bem-estar social vivenciou certa crise, compelindo-o a se envolver em tais atividades, agora sob novos formatos, sobretudo marcados pela contribuição do setor privado ${ }^{4}$.

Disto decorre, no âmbito doméstico, que os direitos administrativos internos sofreram alterações que advieram tanto da ampliação de seu escopo quanto das novas formas de colaboração entre o setor público e privado, dando vazão à percepção de que o estado de bem-estar social teria sido substituído por um estado contratante ${ }^{5} \mathrm{e}$ regulador ${ }^{6}$.

Associado a este movimento, essas relações foram sendo experimentadas com forte elemento de transnacionalidade, conquanto as possibilidades de colaboração com as administrações públicas locais são frequentemente havidas com empresas estrangeiras.

4 Rafael Carvalho Rezende de Oliveira descreve os processos pelos quais o direito administrativo se submeteu para que ocorresse sua transformação paradigmática. Em seu nascedouro, ao tempo das revoluções burguesas, o direito administrativo se apoiou nos preceitos de legalidade e separação dos poderes, afastando-se da máxima de não responsabilidade estatal ("the king can do no wrong"), em um formato em que a atividade da administração era reduzida em função de que ao estado não era dado intervir na autonomia dos agentes privados. À medida em que se consolidou a noção de estado de bem-estar social, esta lógica foi alterada. Passou o Estado a deter a responsabilidade de intervir na economia para correção dos efeitos negativos da economia liberal. Neste prumo, conforme observa, passou a administração a valer-se, com recorrência, de instituto próprio ao direito privado: o contrato. Além disso, as administrações públicas, com vistas a adaptarem-se ao novo contexto, passaram a criar pessoas jurídicas de direito privado com a finalidade de melhor atender aos anseios do welfare state. Por seu turno, a crise havida nos anos 1970 teria revelado desgaste deste modelo, apontando a possível ineficiência das administrações públicas na prestação dos serviços, o que demarcaria o retorno ao particular das atividades econômicas que antes concentrou, cuja relação fez emergir novos modos de contribuições entre setores público e privado (Oliveira, 2009, pp. 68-70).

5 "La vuelta de la repugnancia hacia la Administración empresarial y el ensalzamiento de las liberdades individuales y de la competencia há llevado a una clara recuperación de la primacía de la forma típica de explotación de los servicios en el Estado liberal del siglo XIX. El 'Estado contratante' avanza con paso decidido reduciendo las parcelas del Estado gestor [...]" (Daroca, 2011, p. 13).

6 "En definitiva, como ha afirmado Cassese, pronto se puso de manifiesto que la privatización substituía problemas viejos por nuevos. Las empresas públicas se habían enfrentado a problemas de control interno; las nuevas empresas privadas encargadas de las 'public utilities' planteaban la necesidad de un control externo. Los monopolios públicos presentaban indudables fallos, pero la liberalización podía permitir situaciones de monopolios u oligopolios privados. El 'no mercado' planteaba problemas en la determinación de precios y en la configuración de la oferta y su adecuada correlación con la demanda real, pero el funcionamiento del mercado podía poner en riesgo la regularidad, continuidad, universalidad, calidad y accesibilidad de los servicios. Las críticas y la presión de los consumidores y usuarios imponían la supervisión y fiscalización públicas de las empresas privatizadas. Y de ahí que, paradójicamente, el programa británico de desregulación y privatización generara un incremiento sustancial de la intervención administrativa en la economía. Eso sí, con un tipo de intervención distinta de la característica de la época de las nacionalizaciones. La Administración ya no actúa necesariamente en el mercado como agente empresarial o económico, pero lo regula en aras del interés general, de la competencia y de la protección de los intereses de los ciudadanos, y, además, controla la conformidad de la actuación de las empresas a esta regulación" (Daroca, 2011, p. 16). 
Todo o processo de transformação do campo e do modo de atividade das administrações públicas, impactando nos direitos administrativos, foi impulsionado pela globalização.

Para Thiago Marrara, os fenômenos perceptíveis da transformação do direito administrativo são os da globalização, regionalização e a federalização; a privatização e seus movimentos compensatórios, como a regulação e a agencificação; a consensualização e a contratualização; a democratização e a processualização; e a desburocratização e automação. No tocante à globalização, afirma que a pressão do mercado e o interesse do estado pela atratividade do investimento estrangeiro demandaram a normatização internacional de relações econômicas transnacionais, além de esses espaços normativos se desenvolverem igualmente nos contextos regionais. Vislumbra-se, igualmente, a pertinência de regulamentação multinível no interior do estado: federalização. Já a privatização é vista pelo autor como crítica ao sentido de que toda participação do estado deva ensejar a aplicação de regime jurídico publicista, de onde se apresentam novos modelos de contratação. A seu turno, a passagem das atividades, do setor público ou privado, não ocorre sem que o estado exerça determinado controle sobre a atividade, o que origina sua função regulatória e a consequente criação de agências reguladoras (agencificação) para regulação das atividades. Aumentam-se, ademais, os mecanismos de participação do cidadão na gestão pública (democratização) pelo processo administrativo (processualização). Como também exsurge, a consensualização, tratando do estabelecimento de mecanismos para construção da consensualidade na gestão pública, além da facilitação dos procedimentos visando aumentar a eficiência - desburocratização-e o aumento de novas tecnologias que possibilitam o aprimoramento da gestão pública-automação (Marrara, 2014, pp. 25-42).

Especial destaque deve-se dar à inclusão de diferentes meios de solução de conflitos, dentro do referido processo de transformação, de modo a habilitar a administração pública a tomar parte de procedimentos contenciosos não judiciais ou de meios consensuais de solução de conflitos. Assim foi, no Brasil por exemplo, com a expressa autorização de a administração pública participar de procedimentos arbitrais por meio da promulgação da Lei $\mathrm{n}^{\circ} 13.129 / 15^{[7]}$, a qual incluiu na lei de arbitragem dispositivo que esclarecesse que "a administração pública direta e indireta poderá utilizar-se da arbitragem para dirimir conflitos relativos a direito patrimoniais disponíveis", o que já se autorizava em legislações específicas, sobretudo as correspondentes aos setores econômicos regulados. A alteração foi importante, no país, para encerrar a celeuma provocada pela visão de que a indisponibilidade do interesse público acarretaria a não arbitrabilidade das causas envolvendo a administração pública.

Ela encampa a visão de que há diferentes categorias de interesse público - divididos entre primários e secundários, sendo os segundos aqueles meramente patrimoniais ${ }^{8}$-para

7 Brasil. República Federativa do Brasil. Congresso Nacional. Lei Federal n. ${ }^{\circ} 13.129$, de 26 de maio de 2015.

8 Nas palavras de Carmen Tibúrcio: "a adequada compreensão do ponto exige cautela. Um frequente equívoco na matéria é confusão entre o interesse público propriamente dito - também chamado de 
possibilitar que certos interesses sejam sujeitos à arbitragem. Mas para além disso, é entendimento importante para possibilitar, igualmente, que avance o fenômeno da consensualização do direito administrativo, por também abrir as vias para que a administração pública dos entes brasileiros participe de mecanismos consensuais, incluindo negociações e mediações (Ver Souza, 2014, pp. 487-501) e a formação de Comitês de Resolução de Disputas (Dispute Boards). A consensualização da administração pública, adicionalmente, congrega a participação de cidadãos em conselhos, conferências públicas, audiências, consultas públicas, etc. (Marrara, 2014, p. 40).

Estes movimentos, conjuntamente considerados, demarcam as alterações paradigmáticas sentidas pelo direito administrativo. $O$ fato de a administração pública possuir responsabilidades dentro de contratos complexos, por exemplo, no setor de infraestrutura, geralmente envolvida diretamente com investidor estrangeiro, retira a administração pública da velha posição de expressão única da soberania e autoridade política e a coloca em posição de negociação com agentes econômicos, de forma mais horizontalizada e transnacional. Enfim, o estado que comparece no processo econômico é em tudo diverso do estado todo poderoso de outrora.

É sobre este cenário que autores vêm-se ocupando para esclarecer a emergência de um direito administrativo global. De acordo com Stephan W. Schill, a base material sobre a qual nasce o direito administrativo global tem por fator a ampliação do objeto dos direitos administrativos para lidar com áreas regulatórias como energia, telecomunicações, segurança alimentar, saúde, migração, emprego, antitruste, concorrência, mercado financeiro, e daí por diante. A governança e a atividade regulatória não só demandam perspectivas internacionais como conduziram os direitos administrativos a conhecer formas diferentes de contratação pública, como são as parcerias público-privadas e licitações. Além disso, aumentou-se o aspecto de internacionalidade pela emergência de agências reguladoras com comportamento "extraterritorial" (Schill, 2015, pp. 15-16).

Já no consagrado artigo de Benedict Kingsbury, Nico Krisch e Richard B. Stewart, voltado a tratar dos aspectos embrionários suficientemente consolidados que permitem a constatação de um direito administrativo de caráter global, identifica-se que grande parte das regulações em matérias complexas e de importância transcendente ao estado nacional, no campo do direito administrativo, foi transferida da esfera nacional para a transnacional. À vista disso, formam-se regimes administrados por organizações internacionais ou mesmo emergem grupos informais de funcionários que desempenham funções administrativas não sujeitas ao controle dos estados (Kingsbury; Krisch; Stewart, 2016).

interesse público primário - e o interesse da Administração Pública - ou interesse público secundário. Aquele diz respeito aos próprios fins do Estado, i.e., aos objetivos que justificam a existência da sociedade política, em particular a promoção do princípio da dignidade da pessoa humana pela tutela e efetivação dos direitos fundamentais. Já o segundo corresponde aos interesses instrumentais ou acessórios do Poder Público, como o aumento da arrecadação e a redução das despesas (Tibúrcio, 2018, pp. 122-123). 
Portanto, esta nova situação-do estado frente às economias local e internacional e da realidade das administrações públicas frente ao modo como se relacionam com os serviços de interesse público-reclama maior atenção, do direito internacional público, pelos direitos administrativos domésticos. Nesta senda, por exemplo, encontra-se o esforço da OMC de estabelecer normas jurídicas afetas aos contratos públicos, logrando a conclusão do Acordo sobre Compras Governamentais (Government Procurement Agreement - GPA-), tratando-se de acordo plurilateral visando a abertura dos mercados aos contratos públicos e encartando deveres de transparência e não discriminação.

Para além do escopo próprio do GPA, correspondendo ao estímulo à não discriminação como forma de promover a competitividade transnacional, há no acordo abertura para a promoção de políticas horizontais. Veja-se, por exemplo, a previsão contida em seu artigo XXII (8) (a), estabelecendo que o comitê, criado pelo acordo, realize trabalho adicional que facilite sua implementação ao abordar a situação de pequenas e médias empresas, a coleção e disseminação de dados estatísticos, o tratamento dispensado às compras sustentáveis, as exclusões e restrições das partes aos anexos, e questões de segurança nas compras internacionais. Na opinião de Pedro Cerqueira Gomes, o dispositivo, apesar de expressar a insuficiência do progresso em relação à normatização dessas políticas horizontais, assegura ao menos a continuidade do debate no sentido de que ditas políticas venham a ser garantidas pelo direito internacional global (Gomes, 2015, p. 135).

Com isso, pode-se concluir que a expansão da atenção do direito internacional público ao direito administrativo tende a, futuramente, não apenas cristalizar os deveres de a administração pública local promover suas contratações de modo não discriminatório, mas igualmente buscará favorecer a participação de mais membros ao permitir-lhes certa margem de fomento econômico.

\section{A crise econômica que precedeu a pandemia da covid-19: ainda o elo estabelecido pela aposta nos investimentos estrangeiros}

A expansão das transformações do direito administrativo e da normatização internacional deste ramo jurídico encontra variadas expressões de sua resistência. Uma delas acontece no próprio domínio da teoria do direito administrativo, a qual recusa a ideia de que esta possa-se afastar em demasia do pressuposto da estatalidade (Gontijo, 2014).

Em termos gerais-e envolvendo múltiplas perspectivas-o motivo da resistência é a preocupação de que venha o estado a perder parcela de sua soberania, impossibilitando-o de resolver a questão da dependência econômica, atrofiamento das potencialidades locais e problemas de acessibilidade aos bens e produtos impostas aos seus próprios administrados. E há razões aos estados, sociedades e aos estudiosos para a preocupação!

Por seu turno, a resistência à expansão das transformações e normatização internacional do direito administrativo tende a asseverar-se nos contextos de crise econômica 
internacional, como foram os casos da crise de 2008 e as crises afetando os países em desenvolvimento de 2015.

Conforme levantamento da Comissão Econômica para a América Latina e o Caribe (CEPAL), inclusive, a pandemia da COVID-19 teria afetado a América Latina justamente no momento de sua maior vulnerabilidade econômica, tratando-se de região com pouco espaço para o gasto público, aumento da dívida pública e por ser o período de pior desempenho do Produto Interno Bruto (PIB) (CEPAL, 2020).

Ocorre que, no contexto da crise de 2015, havia cenário relativamente favorável à governança global sobre as matérias das quais se ocupa o direito administrativo, sobretudo por terem os estados tomado medidas de austeridade econômica, diminuindo os gastos públicos nos setores vitais para superação da crise, e confiado nos fluxos globais de investimento como meio de preencher as lacunas do investimento interno.

Tomemos o Brasil por exemplo. Houve, no país, um certo consenso em torno da ideia de que os investimentos em infraestrutura teriam condições de apresentar à economia nacional uma saída à crise. Porém, ditos investimentos não viriam dos gastos governamentais, mas do Investimento Estrangeiro Direto (IED), já que o país apostara suas fichas no discurso da austeridade.

Com isso, uma instituição vinculada ao Senado Federal - a Instituição Fiscal Independente — produziu estudo demonstrando que, de 2015 a 2016, os investimentos públicos brasileiros no setor caíram drasticamente, de modo que não eram suficientes nem mesmo para manter a infraestrutura existente (Salto, 2017).

Observa-se, entretanto, que a aposta brasileira no IED possuía certo êxito, até então, em cotejo aos demais países: no estudo preparado pela UNCTAD — o World Investment Report 2018 - , há notícias de que se, no mundo, os investimentos estrangeiros caíram, em 2017, em 23\%; no Brasil houve aumento de $8 \%$ naquele ano. $\mathrm{O}$ aumento de investimento estrangeiro se deveu àqueles oriundos de companhias chinesas, sobretudo nos setores de energia, petróleo e transmissão de gás, ao lado do tradicional setor da agricultura (UNCTAD, 2018, p. 52).

No entanto, os bons resultados de IED no setor de infraestrutura apresentaram-se como relativos e instáveis, a considerar que a própria Conferência das Nações Unidas sobre Comércio e Desenvolvimento (UNCTAD) constatou queda dos fluxos, no ano de 2018, em 12\% (UNCTAD, 2019, p. 5).

Nestes termos, a oscilação no volume dos investimentos expõe dificuldades impostas a uma visão bem consolidada no âmbito nacional e nas visões econômicas das organizações internacionais de que os investimentos em infraestrutura são importantes para superação da crise, justamente por sua capacidade de gerar condições perenes ao desenvolvimento das potencialidades locais.

Esta realidade possui extrema importância à temática da relação do direito administrativo com a governança global. São os setores de infraestrutura justamente aqueles que, de forma mais aperfeiçoada, submetem-se ao estado gestor e regulador. À vista disso, apesar de turbulento, o contexto brasileiro e toda a característica de seu debate político e econômico, àquela altura, despontava ao sentido de ampliar a adesão 
à governança global, sobre a matéria, como forma de consolidar sua atratividade ao investimento externo.

Nesta esteira, o Brasil teve, nos últimos anos, como debate econômico mais importante, a sua capacidade de atrair investimentos estrangeiros aos setores regulados. Por isso, apesar de a crise ser, genericamente, razão para eventual retração na participação global, afigurava-se uma perspectiva sólida de dirigir esforços ao ambiente externo, o que daria guarida a um contexto pró-governança global.

No entanto, a visão exclusivamente econômica da pertinência da governança global não impediu que, no seio da percepção política brasileira, florescesse visões ideológicas cunhadas sob a perspectiva do nacionalismo - enraizando-se temor irracional ao "globalismo" — a admitirem exclusivamente alinhamento automático com os Estados Unidos da América e desprezando o trabalho realizado pelas organizações internacionais, à semelhança de outros processos políticos pelo mundo.

A pertinência da globalização pela atratividade dos investimentos estrangeiros foi submetida, portanto, ao paradoxo dos possíveis ganhos econômicos confrontados a visões distorcidas a preconceituosas em relação ao ambiente externo. E isso ocorre justamente por conta do medo, a argila com que se constroem ideologias estúpidas.

Neste prumo, não é exagero predizer que o elo fincado pela globalização, sob a ótica do benefício do investimento estrangeiro, não possa demonstrar-se poroso no futuro próximo, precisamente pelos contornos nacionalistas presentes, na atualidade, na política internacional, aliados aos maus resultados econômicos decorrentes da crise que se avizinhava e que se agravou por conta da pandemia.

Pergunta-se, portanto, se a pandemia da COVID-19 não veio a adicionar um novo e aprofundado elemento de porosidade ao consenso estabelecido em torno dos investimentos estrangeiros, o qual servira de base de sustentação ao direito administrativo global.

Claro que, se assim for, os próprios avanços do direito administrativo global encontram-se sob o risco de ser alvo de suspeitas pelas visões nacionalistas, as quais tendem a recursar a perda gradativa da soberania, sobretudo em atividades que se tornaram eixos centrais da economia e que envolvem algum tipo de participação das administrações públicas.

A partir desta constatação é que se posiciona o principal questionamento do presente trabalho: poderia a pandemia da COVID-19 reverter o contexto de otimismo gerado pela aposta nos investimentos estrangeiros? Haverá, no contexto pós-pandêmico, cenário ainda favorável à expansão do direito administrativo global? Estarão os setores regulados sujeitos a maior ou menor grau de normatividade internacional? Quais seriam as possibilidades e os limites do avanço de um direito econômico — que compreenda as atividades públicas — internacional? 


\section{ENFIM, A PANDEMIA}

A pandemia da COVID-19 é o acontecimento de maior relevância do século XXI, ao menos até o presente momento. Entre muitos eventos de grande impacto global — entre atentados, crises, alinhamentos formais e informais - a pandemia representa inovação por exigir, agora mais do que nunca, soluções amplamente globalizadas, intersetoriais e complexas, capazes de superar o vigoroso golpe na economia internacional.

$\mathrm{O}$ acontecimento revelou a ineficiência das políticas públicas de saúde; a ausência de força suficiente da governança global para atingir consenso visando concertação internacional em situações-limite; e demonstrou que a economia não é uma ciência estanque que encontre suas justificações de forma alheia aos fatores sociais, ambientais, sanitários, e daí por diante. Ademais, como dissemos, a pandemia, ainda que seja a última no mundo das realidades, será apenas a primeira no mundo das idealidades.

O horror do rápido espalhamento — em muito devido à propriedade do vírus e sua eficiência de contágio - , o assustador número de mortes e de pessoas com sequelas, além das dores derivadas do necessário isolamento social — as quais não podem ser subestimadas - , certamente marcarão o espectro dos debates políticos nacionais e internacionais. Ainda que a última do mundo das realidades, a pandemia será sempre tida como uma possibilidade temida. Existirá sempre, mesmo que na forma de uma lembrança condicionante.

Em termos de projeção econômica, tem-se a perspectiva de recessão internacional de maior relevo desde a Segunda Guerra Mundial. Adicionalmente, conforme observa a CEPAL, a OMC registrou forte queda no comércio internacional, a qual deverá se dar entre $13 \%$ e $32 \%$ (CEPAL, 2020).

Como não poderia deixar de ser, o fluxo de IED será, com a pandemia, fortemente afetado. Neste prumo, previu-se, no Investments Trends Monitor - Impact of the Coronavirus Outbreak on Global FDI, da UNCTAD, possível queda entre 5\% e $15 \%$ (UNCTAD, 2020, núm. 34), em março, ao que a edição do mesmo documento elaborado quase 20 dias mais tarde já trazia a informação de que a queda poderia corresponder a percentual entre 30\% e 40\% (UNCTAD, 2020, núm. 35).

Para além da queda nos números expressando provavelmente o pior resultado econômico global do século, é preciso esclarecer que a pandemia representa problemas novos em seus significados, já que expôs fissuras no suprimento dos insumos necessários ao seu combate e, por isso, evidenciou deficiência na produção e circulação internacional de bens e serviços (Rafols, 2020, pp. 4-5).

Tome-se, por exemplo, a disputa travada entre países para aquisição de equipamentos médicos, fármacos, máscaras ou respiradores, e a notória carência de produção local de produtos que viabilizassem o tratamento apropriado da enfermidade e das outras tantas agravadas pela falta de leitos em hospitais.

Foi bem este cenário de disputa pelos produtos, por exemplo, que levou a Índia a procurar estabelecer medidas que restrinjam o investimento estrangeiro com vistas 
a evitar "aquisições oportunistas", dada a queda dos valores das ações de companhias nacionais no período de crise.

A ausência de suprimento e inviabilização da implementação de uma campanha integral de combate ao vírus é precisamente o elemento que faz as sociedades voltar críticas à produção e circulação internacionalizada das mercadorias, de modo a associá-la diretamente à carência de recursos, sobretudo para as pessoas mais pobres, revelando um enorme déficit social consagrado pelas políticas públicas globalizadas.

A pandemia, portanto, enquanto realidade ou idealidade, representa uma nova situação, muito provavelmente reforçadora das suspeitas lançadas à governança global. E se o direito administrativo se transformara sobretudo por influência da globalização, a crise econômica e a pandemia da COVID-19 podem representar retrocesso, neste campo. As administrações públicas podem influenciar-se pelo discurso do nacionalismo, da suspeita em relação à normatização internacional e sua própria submissão a procedimentos transnacionais que venham a resolver conflitos. Por isso, ao chamado direito administrativo global, o contexto presente é particularmente desafiador.

\section{A GOVERNANÇA GLOBAL DA GOVERNANÇA GLOBAL: \\ INTERSEÇÕES TEMÁTICAS E AUMENTO DA COERÊNCIA ENTRE REGIMES JURÍDICOS E AGENTES GLOBAIS}

Se até aqui ficou claro que o diagnóstico da situação antes e durante a pandemia é bastante incerto e especulativo, podendo-se esclarecer apenas possíveis riscos e direcionamentos, igualmente é verdade que tanto o prognóstico quanto possíveis remédios aos riscos apresentados possuem níveis consideráveis de incerteza.

Ainda assim, a título propositivo, pode-se dizer que tanto mais a governança global componha um sistema coerente e compreensível aos olhos das sociedades nacionais, mais poderá manter-se estável frente às adversidades postas.

O nível desejável de coerência sistêmica da governança global deve, inclusive, estipular parâmetros de normatização e de atuação frente a situações como a pandemia de COVID-19, as quais possam garantir o bom desenvolvimento as potencialidades locais e a eficácia de resposta para situações de crise, e garantir grau desejável de alinhamento entre as administrações públicas e as organizações internacionais.

A governança global, a partir da pandemia da COVID-19, somente fará sentido aos olhos dos cidadãos no interior dos estados domésticos — favorecendo ampla adesão em seus ideários - caso a possibilidade de ocorrência de uma pandemia esteja contemplada em sua perspectiva; pois, se a última no mundo das realidades, a pandemia da COVID-19 sempre pairará no campo das idealidades, a ponto de outorgar sentido compreensível tão exclusivamente aos encadeamentos que tratem de sua possibilidade abertamente.

$\mathrm{Na}$ atualidade, a governança global se apresenta mais como uma rede de ações e de normas compondo corpos operacionais erráticos do que um sistema uniforme. É claro que isso não corresponde a um demérito da globalização, já que a flexibilidade 
e informalidade foram importantes justamente para que avançasse sobre as diversas temáticas, antes reservadas à atuação exclusiva dos estados.

Assim o é, por exemplo, no direito internacional, sobre o qual milita dúvidas a respeito de sua unidade e sistematicidade, dada sua construção sobre os conflitos de racionalidade presentes numa sociedade globalizada e policêntrica, marcada por diferenciação funcional e por ordens jurídicas heterogêneas, sendo possível apenas o estabelecimento de determinados níveis de interjuridicidade, como entenderam Andreas Fisher-Lescano e Gunther Teubner (Fisher-Lescano; Teubner, 2004, pp. 999-1000).

A percepção de que os regimes jurídicos presentes no direito internacional revelariam um sistema jurídico fragmentado - constituindo "órbitas funcionais", por ser o mundo ainda grande e diversificado demais, como pioneiramente dizia Wilfred Jenks (1953, p. 404) - deveu-se, em grande medida, a uma série de casos em que houve levantamento de normas pertencentes a outros regimes jurídicos que não foram vistas como vinculantes ao órgão judicante responsável pela solução de dado conflito (Ver Silva, 2019).

Neste prumo, ainda que impossível que a sociedade globalizada e o direito internacional público correspondam a um todo uniforme e perfeitamente coeso, é necessário esclarecer que a governança global se aperfeiçoa à medida que reforce as interseções temáticas entre seus diversos corpos operacionais específicos.

Os chamados regimes jurídicos especiais devem envidar todos os esforços para absorver parcela da racionalidade desenvolvida por outros regimes. Por exemplo, devem os regimes que tratam de investimentos estrangeiros e que dirigem normas às administrações públicas locais, com o fim de orientar seu comportamento dentro de uma sociedade globalizada, ser formulados dando-se especial atenção às possíveis vulnerabilidades do estado membro, como as capacidades de obtenção de insumos ou produção própria para responder com eficiência às situações emergenciais a partir de suas políticas públicas.

Para tanto, deve-se recorrer aos trabalhos realizados pela Organização Mundial da Saúde (OMS) para que estes panoramas estejam previamente esclarecidos no momento que os estados assumem obrigações próprias ao direito administrativo global, por exemplo.

Igualmente, referidos trabalhos intersetoriais devem preexistir para que a própria governança global seja capaz de apresentar soluções imediatas aos problemas que se instauram global e rapidamente, como foi o caso da pandemia da COVID-19.

Em suma, o que se sugere é que a governança global esteja preparada para que as sociedades nacionais nela enxerguem eficiência de um ponto de vista complexo, de modo a contemplar uma série de problemas econômicos ou sociais. Somente assim admitiriam que órgãos que tradicionalmente expressavam suas vontades soberanas possam estar sujeitos à solução a partir de concertação internacional de caráter multilateral.

Assim, por exemplo, se o GPA permite que o debate sobre políticas horizontais siga, não há melhor sugestão senão o próprio seguimento do debate. É preciso que os regimes jurídicos aprofundem seus próprios institutos em um sentido interdisciplinar, 
com vistas a absorver normas de caráter social que lhe aprimorem a coerência com necessidades presentes no cotidiano e na vida das pessoas ${ }^{9}$.

Desta forma, o que se recomenda é que a governança global responda à crise da COVID-19 com ainda mais governança global (Rafols, 2020, pp. 14, 27). E não só: com governança global da governança global, no sentido de esclarecer o liame temático entre questões globalizadas ligadas à saúde e as responsabilidades das administrações públicas com o investidor estrangeiro, além dos outros tantos pontos de contato entre as racionalidades operacionalizadas da sociedade globalizada.

Somente sendo mais governança global, poderá esta pretender neutralizar as ameaças dos tempos presentes de crise. O direito administrativo global, portanto, deve-se encaixar cada vez mais às variadas racionalidades sociais que se enraizaram na sociedade globalizada, com vistas a garantir sua sobrevivência a um mundo marcado pelas defesas manifestas e diretas aos nacionalismos "antiglobalistas", a partir de uma inserção global que realmente trate do maior número de riscos possíveis ao bem-estar social no interior dos estados.

\section{CONCLUSÃO}

Vinha o direito administrativo interno dos estados transformando-se, sobretudo no sentido de assumir forma adaptável aos desenvolvimentos oriundos da globalização e da normatização internacional de seu comportamento, com especial ênfase à contratação pública em que é o investidor estrangeiro o contratado.

O cenário de crise econômica, imediatamente anterior à pandemia, apesar de ter favorecido os ideários nacionalistas, não teve o condão de desfazer a noção de pertinência da atratividade do investimento estrangeiro, sobretudo porque era esta a solução apontada para cobrir sua necessidade ante a queda do investimento público.

No entanto, a pandemia da COVID-19 pode representar um avanço da perspectiva "antiglobalista", a assumir postura de não submissão das administrações locais à normatização internacional.

Isto se fala sem necessariamente aderir à perspectiva de que a pandemia da COVID-19 representaria, em absoluto, o fim da globalização. O problema se apresenta de forma graduada, representando recusa à concertação internacional naqueles pontos de extrema sensibilidade aos condicionamentos da vida e do cotidiano das sociedades nacionais.

Nesta perspectiva, a governança global, para se manter, precisa apresentar soluções mais complexas e eficazes aos olhos do cidadão, de modo a transparecer sua eficiência e capacidade de solução de crises, seja lá de qual natureza.

9 Conforme decorre da proposta de Caldera Ynfante, cremos que a forma de obter tal coerência sistêmica para uma governança global capaz de responder à crise sanitária somente pode ser admitida se orientada segundo uma ordem normativa fundada nos direitos humanos (Caldera Ynfante, 2020). 
Isso exige que a governança global seja globalmente governada na direção de reforçar a interdisciplinaridade e complexidade dos assuntos que lhes são submetidos. A governança global deve se afastar dos nexos de causalidade lineares tradicionais para determinação de responsabilidade, incluindo-se novos fatores, sobretudo aqueles que viabilizem o desenvolvimento das potencialidades locais como forma de se criar um aparato razoável que satisfaça as necessidades de insumos, por exemplo, na área da saúde.

Estas soluções precisam estar representadas numa perspectiva preventiva realizada a partir dos trabalhos realizados pelo regime especial que lhe é próprio, e deve influir nos próprios termos dos tratados dos quais o estado se torne parte.

Vendo as administrações públicas uma oportunidade na globalização para superação de emergências, o avanço do direito administrativo global se apresentará como um todo mais coerente e consentâneo aos desafios do século XXI.

\section{REFERÊNCIAS}

Caldera Y. (2020). Jesús E. Biocracia y Derecho Fundamental al Nuevo Orden Mundial en la Postpandemia COVID-19. Utopía y Praxis LatinoAmericana. Revista Internacional de Filosofía y Teoria Social, 25(4), 33-49.

Daroca, E. D. (2011). Crisis y Transformación del Derecho Administrativo. In A. SAdDy e Aurilivi Linares Martínez (coord.), Direito das Infraestruturas: um Estudo dos Distintos Mercados Regulados. Lumen Juris.

DincA, R. (2020). El impacto de la crisis sanitaria de covid 19 en el derecho contractual rumano. Revista de Derecho Civil, VII(2), 109-128.

Fisher-Lescano, A., Teubner, G. (2004). Regime Collisions: The Vain Search For Legal Unity in The Fragmentation of Global Law. Michigan Journal of International Law, 25(4).

Gomes, P. C. (2015). Políticas Horizontais no novo Goverment Procurement Agreement (GPA). Revista de Contratos Públicos (RCP), 4(7), 191-140.

Gontijo, D. C. A. (2014). O Novo Direito Administrativo: Uma Criatura de Dr. Frankstein? Fórum Administrativo: Direito Público, 14(164).

JENKS, W. (1953). The Conflict of Law-Making Treaties. (30) Britisb Yearbook of International Law. Kingsbury, B., KRisCH, N., Steward, R. B. (2016). A Emergência de um Direito Administrativo Global. In M. RATTON SANCHEZ BADIN (org.), Ensaios sobre o Direito Administrativo Globale Sua Aplicação no Brasil. FGV Direito.

Marcos, A. (2020). Com COVID y sin COVID: La Vulnerabilidad Humana. Cuadernos de Bioetica, $31(102), 139-149$.

Marrara, T. (2014). Direito Administrativo Brasileiro: Transformação e Tendências. In Direito Administrativo Brasileiro: Transformação e Tendências. Almedina.

OliveirA, R. C. R. (2009). O Princípio da Participação na União Europeia: O Direito Administrativo Comunitário em Busca de uma Legitimidade Renovada. In A. SADDY ALMEIDA (coord.), Direito Público Econômico Supranacional. Lumen Juris. 
Rafols, X. P. (Junho de 2020). La COVID-19, la Salud Global y el Derecho Internacional: Una Primeira Aproximación de Carácter Institucional. Revista Electrónica de Estudios Internacionales, (39), 1-29.

Salto, F. (2017). Crise Econômica, Regras Fiscais e Dívida Pública. Instituição Fiscal Independente. https://www12.senado.leg.br/ifi/pdf.

SCHILL, S. W. (2015). Abordagens Jurídicas Transnacionais sobre Direito Administrativo: a Conceituação dos Contratos Públicos na Globalização. Revista de Direito Administrativo, $268,13-53$.

Silva, E. MEndonça Dias DA. (2019). Direito Internacional e o Debate sobre sua Unidade. Editora dos Editores.

Souza, L. M. (2014). Resolução de Conflitos Envolvendo o Poder Público: Caminhos para uma Consensualidade Responsável e Eficaz. In T. MARrara (org), Direito Administrativo: Transformações e Tendências (pp. 487-501). Almedina.

Tibúrcio, C. (2018). Arbitragem Envolvendo a Administração Pública: Arbitrabilidade Subjetiva e Objetiva. Histórico e Situação Atual. In J. DE PAIva Muniz e outros (coord.), Arbitragem e Administração Pública - Temas Polêmicos. Migalhas.

Tura, M. A. R. e Silva, E. Mendonça Dias Da. (2018). Arbitragem de Investimentos Estrangeiros. In J. DE PAIVA MUNIZ e outros (coord.), Arbitragem e Administração Pública-Temas Polêmicos. Migalhas.

TurA, M. A. R. (2009). Soberania Estatal e Classes Sociais. Alfa Ômega, 2009.

\section{Documentos}

CEPAL. Dimensionar los Efectos del Covid-19 Para Pensar En La Reactivación, 2020. https://www. cepal.org/es/publicaciones/45445-dimensionar-efectos-covid-19-pensar-la-reactivacion (acessado em 6.9.2020).

UNCTAD. Investment Trends Monitor-Impact of the Coronavirus Outbreak on Global FDI. n. ${ }^{\circ}$ 34. March, 2020. https://unctad.org/en/pages/publications/Global-Investment-TrendsMonitor-(Series).aspx (acessado em 10.9.2020).

UNCTAD. Investment Trends Monitor-Impact of the Coronavirus Outbreak on Global FDI. n. ${ }^{\circ}$ 35. March, 2020. https://unctad.org/en/pages/publications/Global-Investment-TrendsMonitor-(Series).aspx (acessado em 10.9.2020).

UNCTAD. World Investments Report - Investments and New Industrial Policies. United Nations, 2018.

UNCTAD. Investment Trends Monitor. n. ${ }^{\circ}$ 31. January, 2019. https://unctad.org/en/pages/ publications/Global-Investment-Trends-Monitor-(Series). aspx (acessado em 10.9.2020).

\section{Leis}

Brasil. República Federativa do Brasil. Congresso Nacional. Lei Federal n. ${ }^{\circ}$ 13.129, de 26 de maio de 2015 . 